\title{
A produção do conhecimento nas Ciências Sociais e a provisoriedade da realidade material e simbólica*
}

\section{The production of knowledge in Social Sciences and the temporary aspect of the material and symbolic reality}

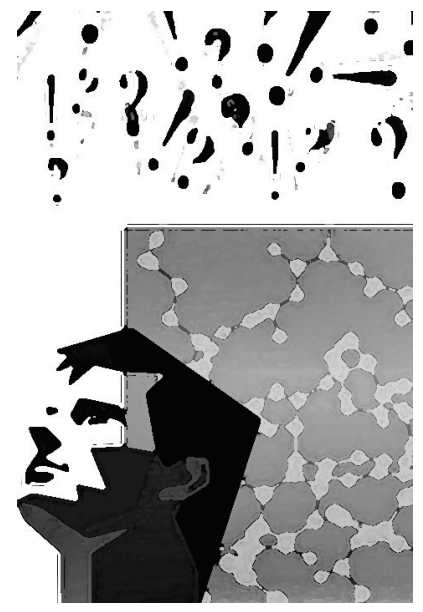

\author{
Maria do Socorro F. Osterne** \\ Glaucíria Mota Brasil**** \\ Rosemary de Oliveira Almeida****
}

Resumo: O presente artigo aborda as polêmicas e contradições que têm acompanhado as discussões acerca da cientificidade no campo das Ciências Sociais e suas controvérsias paradigmáticas no intuito de pensar a realidade social. Advoga a ideia do devir, a historicidade e o caráter ideológico do processo de conhecimento, além da inexistência de um único método científico. Destaca a relação sujeito e objeto no processo de objetivação do conhecimento e do vínculo com o empírico, sem esquecer que a objetividade é a utopia da ciência. Por fim, enfatiza as exigências do método científico, na condição de constituição de métodos rigorosos e flexíveis que consideram a dinâmica e a provisoriedade da realidade material e simbólica.

Palavras-chave: Ciência. Cientificidade. Métodos e ciências sociais.

* Artigo originado da reflexão e experiência das autoras pesquisadoras no trato de seus objetos de pesquisa.

** Professora do curso de Serviço Social e do programa de pós-graduação em políticas públicas e sociedade da Universidade Estadual do Ceará (Uece), Fortaleza/CE, Brasil; doutora em Serviço Social pela Universidade Federal de Pernambuco.E-mail: socorro.osterne@uece.br.

*** Professora do curso de Serviço Social e do programa de pós-graduação em políticas públicas e sociedade da Universidade Estadual do Ceará (Uece), Fortaleza/CE, Brasil; doutora em Serviço Social (PUC-SP) e pesquisadora do CNPq. E-mail: gmotabrasil@gmail.com.

**** Professora do curso de Serviço Social e do programa de pós-graduação em políticas públicas e sociedade da Universidade Estadual do Ceará (Uece), Fortaleza/CE, Brasil; doutora em Sociologia. E-mail: rosemary.almeida@uol.com.br. 
Abstract: This article deals with the controversies and contradictions that have followed the discussions about the scientific character in the field of Social Sciences and its paradigmatic controversies in order to think about the social reality. It supports the idea of the becoming, the historicity and the ideological nature of the process of knowledge, as well as the absence of a single scientific method. It emphasizes the relationship between subject and object in the process of objectification of knowledge and the link with the empirical, having in mind that objectivity is the utopia of Science. Finally, it stresses the requirements of the scientific method in relation to the constitution of flexible and rigorous methods that consider the dynamics and the temporary character of the material and symbolic reality.

Keywords: Science. Scientific character. Methods and social sciences.

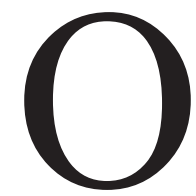

campo científico, apesar de sua natureza metódica, é atravessado por conflitos e contradições. Historicamente, não foram poucas as tentativas de uniformização de procedimentos para a produção do conhecimento nas Ciências Sociais como pré-requisito para seu estatuto de ciência. São, portanto, inúmeros os questionamentos em torno da cientificidade, e muito já se falou sobre a "crise de paradigmas" no âmbito das Ciências Sociais. O fato é que as Ciências Sociais sempre estiveram às voltas com acirradas polêmicas em torno de seus modelos teóricos. Daí os questionamentos sobre a possibilidade de serem as controvérsias paradigmáticas algo inerente à própria natureza dessa área do conhecimento.

A rigor, a discussão específica sobre os paradigmas, em sua gênese mais atual, não emergiu no marco das Ciências Sociais, mas no seio da Física, com fortes rebatimentos na elaboração da chamada Nova Filosofia da Ciência.

Foi no interior desse processo que, em 1962, Thomas Kuhn, na sua famosa monografia, A estrutura das revoluções científicas, definiu o paradigma como uma "constelação que compreende globalmente leis, teorias, aplicações e instrumentos" e que possibilita "um modelo que engendra uma tradição particular de investigação científica" (2006, p. 8).

É importante destacar que Kuhn (2006) restringe sua análise às ciências que ele próprio caracteriza como "paradigmáticas", ou seja, aquelas que dispõem de um paradigma compartilhado pela dita comunidade científica e, para ele, as ciências referidas ao social são "pré-paradigmáticas". Não se pode ignorar que a própria noção de paradigma é problemática quando se trata das Ciências Sociais.

Por outro lado, Kuhn ensinou-nos que as observações que fazemos sobre um dado fenômeno da realidade não são "puras", mas produzidas pelos nossos 
conceitos; ou seja, não existem "fatos" dissociados das ideias que utilizamos para descrevê-los.

Aqui é mais pertinente tratar o debate na área do social numa abordagem que o apreenda mais como polêmica inerente aos conhecimentos referidos à sociedade do que como influxo da controvérsia na Física, como sugere Netto (1992). Nessa linha de raciocínio, o autor considera que o embate no âmbito das Ciências Sociais passa por duas vias diferenciadas: a primeira seria o questionamento do paradigma positivista; a segunda, o questionamento da racionalidade na crise da modernidade.

O paradigma positivista é alvo de críticas seculares. A mais importante dessas críticas é, sem dúvida, aquela situada na tradição marxista, embora possam também ser encontradas na sociologia compreensiva de Weber, na fenomenologia de Husserl, enfim, nas derivações do historicismo alemão.

$\mathrm{Na}$ esteira dessas críticas emergiu o questionamento da racionalidade na crise da modernidade. O princípio é que há uma crise de cultura e de civilização - vinculada ao fracasso das promessas da modernidade, compreendidas como o grande projeto histórico-social e cultural, herdeira do Iluminismo, relacionava a racionalidade do controle sobre a natureza com a emancipação e a liberação dos homens (Netto, 1992).

A defesa da razão, da racionalidade como instrumento de controle e exploração da natureza para garantir um produtivismo que possibilitaria a liberação e a autonomia dos indivíduos tornou-se uma promessa não realizada da modernidade. Assim, as pessoas foram cada vez mais submetidas a uma progressiva heteronomia, ou seja, a novas formas de dominação, exploração, opressão e de sujeição. A esse tipo de racionalização da vida em sociedade, Max Horkheimer (1990), da Escola de Frankfurt, vai nominar, em sua teoria crítica, de razão instrumental, e a esta vai opor a razão crítica. Assim como fará Habermas (1994), também frankfurtiano, em sua teoria da ação comunicativa. ${ }^{1}$

1. Jürgen Habermas (1929) é um filósofo e sociólogo alemão que tem seu nome associado à Escola de Frankfurt (esta responsável pelo lançamento dos fundamentos da chamada "teoria crítica" ou um conjunto de ideias sobre a cultura contemporânea com base no marxismo não ortodoxo, abertas às influências que o pensamento exerce sobre todas as premissas teóricas), cujos principais representantes são Adorno (19031969), Marcuse (1898-1979), Benjamin (1892-1940) e Max Horkheimer (1895-1973). Embora haja diferenças de pensamento filosófico entre eles, um tema comum atravessa sua obra, que é a crítica radical à sociedade industrial moderna. 
Com a instrumentalização da razão, a Ciência nega não só a possibilidade real de acesso ao conhecimento científico, como o espírito iluminista de emancipação da raça humana.

É previsível, portanto, que os modelos de análise tenham assumido versões contemporâneas peculiares em face das determinações históricas e da própria evolução do pensamento no interior das diferentes matrizes analíticas. Em síntese, o que se passou a questionar foram os paradigmas de racionalidade que se afirmaram no processo da modernidade.

Feitas essas observações de ordem mais geral, cabe-nos fazer a seguinte indagação: o que está se destacando como novo na forma de pensar as realidades sociais?

De fato, desde as últimas décadas do século $\mathrm{XX}$, as Ciências Sociais vêm ampliando os limites de seus questionamentos, suas fontes de reflexão e seus meios de pesquisa. Para Martins, Eckert e Novaes (2005), essa área do conhecimento transformou-se e se enriqueceu diante da multiplicidade de inovadoras e diversas formas de expressão e reflexão na produção científica.

Posturas conceituais e epistemológicas renovadoras e criativas dissolvem dicotomias obsoletas, demarcações seguras e duradouras. Revelam ou sugerem um grande elenco de temas possíveis e problemas que haviam sido ocultados nos cuidados próprios dos formalismos acadêmicos. (p.12)

Esses mesmos autores acrescentam que as Ciências Sociais têm uma tradição de interdisciplinaridade e, sobretudo agora, abrem-se com mais vigor para as trocas entre as disciplinas, aos diálogos teóricos entre "o uno e o múltiplo", alargando a tradição crítica na produção teórica e na troca de conhecimento com a sociedade para além das fronteiras estritamente acadêmicas.

Sugerem que se vive hoje uma nova era nas Ciências Sociais, marcada pelo questionamento das certezas e por uma visível busca de reformulações, alargamentos, rupturas conceituais e teóricas, questionamentos dos meios de pesquisa, de técnicas e de método. Reconhecem que no Brasil já aparece uma significativa criatividade nas instituições acadêmicas, mesmo que, às vezes, tímida, assim como uma consciência da necessidade de revisão crítica e criativa do diálogo com a sociedade, com os movimentos sociais enfim, com os chamados novos sujeitos. Ainda para Martins, Eckert e Novaes (2005, p.13), 
[a]s novidades sociais, os novos relacionamentos, as novas modalidades de ação, as novas necessidades sociais, surgidos com as rupturas relacionadas com o regime militar, levaram a novas institucionalizações, enrijecimentos, preocupantes certezas "definitivas", multiplicação de contradições e desafios para a sociedade e, portanto, também para as ciências sociais.

O cotidiano inseguro, a experiência incerta e o sentido da ação são elementos essenciais para o conhecimento nas Ciências Sociais. Manifesta-se, assim, a busca de um saber pertinente, na medida em que este se volta não apenas para os aspectos formais do método científico e de seus estatutos racionalmente ordenados, como também para a informalidade, para o inusitado do cotidiano desordenado. A ciência tece junto campos antes considerados distintos, como a totalidade estruturada e racionalizada do mundo econômico e político e as estruturas cotidianas constitutivas das experiências emocionais e psicológicas, como nos ensina Morin na concepção do conhecimento complexo:

O conhecimento pertinente deve enfrentar a complexidade. Complexus significa o que foi tecido junto; de fato, há complexidade quando elementos diferentes são inseparáveis constitutivos do todo (como o econômico, o político, o sociológico, o psicológico, o afetivo, o mitológico), e há um tecido interdependente, interativo e inter-retroativo entre o objeto de conhecimento e seu contexto, as partes e o todo, o todo e as partes, as partes entre si. (2000, p. 38)

Aspecto fundamental é compreender que as Ciências Sociais se constituem como experiência artesanal de cultivo da imaginação sociológica, para desenvolver o raciocínio (Mills, 1980), em busca do sentido do conhecimento e da compreensão do mundo. É possível fazer ciência racional, nestes termos, na medida em que há uma profunda imersão nas experiências da vida articuladas com a elaboração intelectual, o que resulta na interpretação do mundo e das interações sociais em sua diversidade.

Assim, não se advoga um método em detrimento de outro, mas a possibilidade de conhecer mediante conceitos e incursões metodológicas, sem, no entanto, utilizá-los como concluídos, mas articulando com as experiências, os sentidos e as urgências de compreensão do mundo social. A pretensão é:

dilatar os sentidos, ampliar o horizonte da compreensão, encontrar novos caminhos e percorrer antigas trilhas. Fazer honra à complexidade nos leva hoje a dedicar-nos à 
tarefa de insuflar sentido. É necessário rastrear a rica rede de relações na que um acontecimento há sido tecido, tratar de expandir o universo dimensional de nossa experiência e de nossa historização, sabendo sempre que é impossível seguir todas as pistas, ou suspeitar ao menos da sua existência - entre outras coisas porque vão surgindo em nossa própria atividade de elaboração. (Najmanovich, 2003, p. 25)

Não é, pois, ao acaso que se venha observando uma ênfase destacada nas expressões da experiência e, em especial, nos atores sociais. O que, de certa maneira, corrobora com a contemporaneidade do pensamento político de Hannah Arendt (1992), expresso na seguinte afirmação da autora: "Eu não creio que possa haver qualquer processo de pensamento sem experiência pessoal. Todo pensamento é repensado: ele busca depois da coisa" (p. 41). O que, na verdade, pode ser observado em toda sua obra, ou seja, a marca das suas experiências de vida com o totalitarismo, a violência e a barbárie. Coloca-se hoje em evidência, portanto, a relevância dos sentidos das ações e a busca da construção dos significados, a valorização do estudo dos discursos, da linguagem, em suma, o sentido das palavras.

Pode-se, assim, afirmar que o "universalismo dos filósofos iluministas já não nos serve mais de guia" (Ortiz, 2012, p. 6) ou como constata o autor em seu trabalho, a existência de um mal-estar do universalismo. Para ele essa questão torna-se paradoxal no

momento em que determinada situação histórica aproxima a todos, o universal, como categoria política e filosófica, perde em densidade e convencimento. Ressurge, assim, um debate antigo, mas que agora se reveste de formas distintas: o relativismo. Este é um tema clássico nas ciências sociais devido à natureza do próprio saber sociológico. A existência de diversas correntes teóricas revelam as dificuldades para a constituição de um paradigma único, capaz de se impor para a disciplina como um todo. Há ainda outros importantes: eles são históricos, e a subjetividade de seus praticantes é uma dimensão decisiva no entendimento dos fenômenos sociais. Entretanto, apesar das controvérsias, os embates teóricos tendem a se concentrar num problema comum, qual seja, em que medida as explicações sociológicas ou antropológicas teriam ou não abrangência "universal" [...]. A dúvida, como em qualquer outra atividade científica, seria o de delimitar a validade do pensamento, retirando-o dos traços restritivos de cada experiência. A discussão focaliza, portanto, temas de caráter teórico e metodológico. Mas a questão da diversidade das interpretações pode ser abordada de outra forma, considerando-se não tanto os impasses do método, mas como as ciências sociais se constituem historicamente. Neste caso, somos obrigados a nos perguntar sobre o contexto no qual elas se realizam. (Ortiz, 2012, p. 7-8) 
Na esteira dessa discussão paradigmática, observa-se, pois, como uma grande virada, as análises dos processos de simbolização e representação, que é o campo da cultura propriamente dito. Já é possível perceber um visível crescimento dos estudos literários ou culturais, da teoria crítica, que terminam por evidenciar a literatura, a filosofia, as artes e as humanidades de maneira geral. Do mesmo modo, também constata-se ênfase nas análises dos processos de subjetivação e da construção da subjetividade, além da valorização da vida cotidiana como dimensão das conquistas fundamentais do gênero humano. Tudo isso tem influenciado o crescimento do interesse pela fenomenologia e pela hermenêutica, abordagens já tradicionalmente dedicadas aos estudos dessas questões.

Nessa busca de compreender o novo, nota-se o reconhecimento de grande parte dos pesquisadores das Ciências Sociais sobre a impossibilidade de o pesquisador fechar-se em um único paradigma e a necessidade da comunicação, da interconexão ou transconexão entre paradigmas como perspectiva teórico-metodológica de explicação da realidade.

Essas exigências de intercomunicação, ou melhor, da transcomunicação nos processos de descrição, compreensão e análise, pode aparecer de diferentes formas, tais como na síntese entre micro e macro nas abordagens teóricas; na relação entre estrutura e sujeito; na demanda de interligação entre processos estruturais e práticas sociais e, ainda, quando os pesquisadores destacam a relação entre enfoque de estrutura e enfoques culturalistas.

Essas questões podem ser vistas, por alguns, como relativismo e para outros significa relativizar (Da Matta, 1987) para criar condições de possibilidades para o alargamento dos horizontes teóricos e flexibilidade de análise para ser o mais fiel possível ao dado da realidade, ou seja, estar aberto para incorporar as dimensões criativas da realidade social, para acolhê-la em suas múltiplas manifestações, o que significa não vesti-la com a camisa de força de dogmatismos teóricos e ideológicos. Afinal, toda realidade é sempre muito mais rica e complexa do que a possibilidade de compreensão, análise e explicação que se faça sobre esta. O processo de conhecimento da realidade é também desconhecimento desta, uma vez que nenhuma realidade será desvelada na sua totalidade.

Para que o pesquisado possa estar aberto para incorporar as dimensões criativas da realidade social, tendo como perspectiva teórico-metodológica a comunicação e as múltiplas conexões entre os paradigmas, precisará estar sempre atento e atualizado no tocante aos processos de conhecimento e dos seus resultados. Do 
contrário poderá não saber reconhecer os limites entre a necessária abertura teórica e o ecletismo. Se o ecletismo está presente na composição de uma revisão de literatura que antecede a busca do estado da arte de um tema, por outro lado, provocaria efeitos nefastos no momento da adoção de um marco teórico referencial.

Nesse cenário, é necessário enfatizar a importância de o pesquisador estar atento às exigências do alargamento do pensamento crítico e investigador. Para não aceitar é preciso conhecer, assim como para conhecer é preciso exercitar a imaginação sociológica (Mills, 1980) no sentido mais amplo da produção do conhecimento nas Ciências Sociais. O indivíduo que exercita o senso crítico é um espírito indagador que se estranha com o habitual e, como Bertold Brech, acredita que "nada deve parecer natural, nada deve parecer impossível de mudar”. Só assim poderá acolher as dimensões criativas da realidade.

É oportuno ainda destacar que não há como ficar apenas nos "significados", pois, o horizonte das transformações pressupõe romper com as estruturas arcaicas. É claro que o simbólico e as representações sociais têm grande importância na reprodução das estruturas objetivas e cognitivas. E é exatamente por isso que se torna necessário entender mais profundamente como o simbólico e as representações sociais produzem e são reproduzidos pelas estruturas econômicas, políticas, pela família, pelo parentesco, pela sociedade enfim. As palavras (o dito) são muito importantes para entendermos como as coisas se reproduzem, assim como também o não dito. Ter conhecimento das palavras ditas e não ditas é pré-requisito para pensar e fazer as mudanças acontecerem.

Assim, parece ser perfeitamente factível a possibilidade de diálogo do marxismo com outros paradigmas contemporâneos, com as versões culturalistas e com as abordagens do cotidiano. Afinal de contas, o marxismo, para manter coerência com sua base teórico-crítica, precisa estar posto como uma perspectiva teórica alargada. Por outro lado, é sempre oportuno enfatizar a necessidade de os fundamentos de fonte marxista ser analisados por estudos consistentes. Só assim será possível enxergar os limites do marxismo e suas possibilidades atuais como referência analítica no campo das Ciências Sociais. Como assevera Pierre Bourdieu, "[é] evidente, por exemplo, que Weber viu o que Marx não via, mas também que Weber pôde ver o que Marx não via porque Marx viu o que viu" (2004, p. 51).

Weber utilizou termos como "infraestrutura" e "superestrutura", palavras-chave do materialismo histórico de Marx, sem, no entanto, compartilhar teoricamente com o autor. Analisou o capitalismo moderno utilizando-se de termos como 
fatores econômicos e materiais, parecendo corresponder ao marxismo, "mas ao mesmo tempo afastava-se do materialismo histórico ao negar a possibilidade de encontrar-se um curso objetivo e determinado dos processos históricos" (Cohn, 2000, p. 13). Ao fazer isto, ele queria se contrapor às versões idealistas da época, percebendo a tese da acumulação do capital e dos estudos econômicos marxistas, mas buscava compreender, para além, o processo de racionalização da conduta dos indivíduos que só pode ser encontrada na particularidade histórica e empírica em que se estuda de onde advinha a interpretação dos sentidos culturais da ação capitalista para além do econômico.

Na concepção weberiana, tais sentidos subjetivos da ação são pensados por sujeitos ao se referirem à conduta de outros, a partir da qual encontram motivos e se orientam na ação. São sentidos subjetivos, individuais, independentes daqueles já dados, que buscam as causas da ação e são objetos de interpretação orientada por um fim (Weber, 1991).

A relevância dos dois autores clássicos para as Ciências Sociais permanece incontestável. Trata-se aqui de levantar questões pertinentes que englobam e alimentam as teorias, na medida em que põem na ordem do dia a exigência de uma postura alargada e crítica que proporcione: o diálogo entre as teorias, evitando, porém, o ecletismo e também o dogmatismo; a conexão das abordagens micro e macro; as articulações estruturais e intersubjetivas no enfoque de comportamentos concretos, simples e "insignificantes"; a abordagem do cotidiano e a existência do sentido na busca da relação entre estrutura e sujeito para explicar a realidade social. Tendências estas, diga-se de passagem, destacadas desde a década de 1990.

Podemos afirmar que essas questões continuam fecundas no momento atual, diferenciadas, contudo, pelo não crescimento, pela terceirização e pelo sucateamento de parte do ensino superior público, pela má qualidade das bibliotecas, pelos parcos recursos para a pesquisa e pelo empobrecimento dos docentes e discentes que se fragilizam no sentido de levar a efeito uma vida acadêmica de qualidade.

Além do mais, percebe-se que a pesquisa, principalmente em sua dimensão epistemológica e metodológica, não vem, efetivamente, perpassando todo o processo de formação dos profissionais nos cursos de graduação. Localiza-se em determinadas disciplinas e ainda é uma prática assumida, por poucos grupos, como atividade de iniciação acadêmica. Observamos também que muitas pesquisas terminam sendo reafirmações de coisas já ditas, não acrescentando outras informações às experiências. 
Da Matta (1978), como articulista do livro A aventura sociológica: objetividade, paixão, improviso e método de pesquisa, fala do problema do "divórcio" entre o pesquisador e a realidade:

[...] o divórcio entre o pesquisador e a tribo, a classe social, o mito, o grupo, o ritual, o bairro, as pessoas, o sistema de relações sociais, o modo de produção, o sistema político e tantos outros domínios da realidade a ser conhecida. (p. 24)

Esse divórcio, na concepção do autor, não diz respeito somente à "ignorância" do estudante. Ao contrário, pode até estar relacionado ao excesso de conhecimento. Um conhecimento, porém, teórico, universal e mediatizado, não pelo concreto e principalmente pelo específico, mas pelo abstrato e pelo não vivenciado. Mediado pelos livros, ensaios e artigos, enfim, pelos outros.

Essa discussão de cunho mais filosófico, epistemológico e metodológico da pesquisa, no interior do processo de formação profissional, continua sendo um desafio essencialmente pertinente ao momento atual e pressupõe o exame dos chamados paradigmas de análise da realidade social nesse início do século XXI.

Uma realidade desafiante que, ao lado de problemas mais remotos relacionados à ainda ampliada reprodução da miséria e da fome, à manutenção da opressão de classe, raça/etnia e gênero, às dificuldades no trato com a saúde, educação e segurança e do mau uso da política, passa a conviver com problemas mais recentes, tais como: a destruição do meio ambiente e a degradação das condições de vida, a violência em suas diversas formas de manifestação, os particularismos e os individualismos, as hostilidades étnicas, as discriminações, os preconceitos, o uso e o tráfico de drogas, o crime organizado e tantas outras situações, que ao expressar novos desafios, colocam novas temáticas e apontam para novas tendências de análise.

Sabe-se que, para a pesquisa, o movimento da realidade social e suas demandas, e as perspectivas teórico-metodológicas encarregadas de reconstruir essa realidade, são dimensões fundamentais à sua finalidade. A ideia básica é não esquecer que a teoria não pode ser outra coisa senão a (re)construção em nível do pensamento do próprio movimento da realidade. Neste sentido, toda e qualquer teoria, por maior que tenha sido o rigor do método, será sempre muito mais limitada do que a realidade em si. Em outras palavras, qualquer conhecimento é aproximado e construído, ou seja, o conhecimento pressupõe um método de raciocínio, nunca uma verdade. 
Para Ladrière (1977), quando se quer chegar a um conhecimento da realidade social é preciso captá-la em sua própria produção, isto é, na ação. É imperativo considerar a ação nela mesma, no seu processo de efetuação, não em seu efeito. Ora, os efeitos são passíveis de observação. A ação em si não o é. Porém ela pode ser compreendida a partir dela mesma. Deduz-se dessas considerações que algumas ciências, como, por exemplo as Ciências da Natureza, podem ser explicadas; outras, como é o caso das Ciências Sociais, só podem ser compreendidas.

Os dilemas entre as condições de possibilidade do uso do esquema da explicação, que, por sua vez, utiliza a linguagem do sistema e do uso do esquema da compreensão que utiliza a linguagem do sentido, são inúmeros.

Nesse sentido, Ladrière (1977) indaga se a opção por tratar os fatos sociais "como coisa", através das regras formais, não seria rejeitar o que é da ordem das significações, das intencionalidades, das finalidades e dos valores inerentes à face interna da ação. Por outro lado, pergunta se ao acolher o caminho da "compreensão" não estaria se arriscando a uma perspectiva essencialmente subjetiva. $\mathrm{O}$ autor sai do impasse sugerindo que o essencial não é encontrar efetivamente um acordo a respeito de qual é o conteúdo determinado do conhecimento, tampouco fundar um método universalizante.

Para ele, a cientificidade representa uma ideia reguladora, não um modelo determinado e constituído de uma vez por todas. Sua opinião é que se torna impossível definir uma metodologia das Ciências Humanas tendo como diretriz uma ideia de cientificidade já construída. Acrescenta que: "Na realidade histórica de seu devir, o procedimento científico é ao mesmo tempo aquisição de um saber, aperfeiçoamento de uma metodologia, elaboração de uma norma" (Ladrière, 1977, p. 11). Se a epistemologia é possível, continua argumentando, deve-se ao fato de que a ciência já funciona e, no funcionamento que lhe é endógeno, certa ideia reguladora já se manifestou parcialmente.

Dessa reflexão infere que a epistemologia deverá dirigir sua atenção não para os resultados, não para a ciência já construída, mas para os procedimentos, ou seja, para o devir. Em síntese, para tudo aquilo que faz da atividade investigativa uma tarefa categoricamente prospectiva.

Percebe-se, então, que o mais importante nessa ordem de lógica é compreender, com precisão, de que forma a pesquisa pode ser criadora, como pode fazer aparecer não somente novos resultados, mas novos métodos para que a ideia de cientificidade possa assumir, progressivamente, contornos mais precisos, controlar 
a si mesma e se tornar mais eficaz para adaptar-se de forma cada vez mais estreita a seu objeto.

Neste ponto é oportuno voltar a Morin (1991), com o "paradigma da simplicidade", referido para se contrapor ao método cartesiano e enaltecer a presença do outro, a humildade, a abertura, o rigor e a tolerância, a provisoriedade do conhecimento e a emergência do incerto e do aleatório na vida das pessoas. Nessa mesma linha de raciocínio Martins (2000), em sua defesa da sociabilidade do homem simples, afirma que

[é] nos limites, nos extremos da realidade social que a indagação do cientista se torna fecunda. A explicação sociológica é incompleta e pobre se não passa pela mediação do insignificante. São nessas situações de protagonismo oculto e mutilado dos simples, do homem sem qualidade, que a sociedade propõe ao sociólogo suas indagações mais complexas, seus problemas mais ricos, sua diversidade teoricamente mais desafiadora. São os simples que nos libertam dos simplismos. O relevante está também no ínfimo, na vida cotidiana fragmentária e aparentemente sem sentido. (Contracapa)

Ainda, sobre a possibilidade do simples na ciência e na pesquisa, Ginzburg (1989) apresenta a metáfora do caçador, aquele que busca conhecer mediante uma longa aprendizagem de observação detalhada, aprendendo a "farejar, registrar, interpretar e classificar pistas" (p. 151). Significa não descartar o aparente insignificante, o simples, facilmente negligenciáveis pelos pesquisadores, mas profundamente notáveis para outros atentos aos resultados e à produção de um saber dos pormenores empíricos reveladores de fenômenos profundamente enraizados na dinâmica da realidade estrutural e estruturante.

É, portanto, partindo da construção do objeto que se conseguirá captar o aspecto dinâmico do procedimento científico. Essa construção, contudo, é uma operação contínua. Nunca poderá ser considerada conclusa, uma vez que, a partir do instante em que se consegue descolar o objeto da situação problemática na qual se encontrava, ele logo suscitará, em seu próprio movimento, novos problemas.

Com o testemunho da história, sabe-se que sempre existiu uma forte preocupação do homem com o conhecimento da realidade. Por intermédio dos mitos, das religiões e das filosofias muito se tem produzido sobre o significado do mundo da vida. Minayo (1994) lembra que a poesia e a arte continuam desvendando lógicas do consciente coletivo, do cotidiano e do destino humano. Enfatiza que a ciência é 
apenas uma dessas formas de buscar o conhecimento, "não exclusiva, não conclusiva, não definitiva", embora hegemônica na sociedade ocidental (p.10).

A ciência não é simplesmente o prolongamento da visão espontânea do mundo, ou uma formulação um pouco sofisticada do que se oferece à percepção. Ela só consegue fazer com que captemos aspectos inéditos da realidade na medida em que começa por substituir o campo perceptivo por um domínio de objetos que ela constrói por seus próprios meios. (Ladrière, 1977, p. 19)

Assim, a unidade da ciência será sempre problemática, pois ela constitui-se muito mais um campo de heterogeneidade entre disciplinas que se articulam e entre saberes que se encontram alimentados por interações conceituais. Não é una, é múltipla como conhecimento possível. Insere-se num devir constante e contínuo. Em decorrência é possível concluir que não existe um método científico. No máximo o que se tem é uma noção de método científico. Ou seja, procedimentos metódicos que permitem penetrar a essência dos fenômenos naturais, humanos e sociais por intermédio da experimentação.

Passeron (1995) prefere a compreensão ampliada da aproximação de duas ciências históricas e sociais - a sociologia e a história - a partir da qual compõe a possibilidade do raciocínio sociológico como ciência empírica da interpretação, mesclada pela argumentação metodológica experimental ou quantitativa e pela contextualização histórica, no chamado vaivém argumentativo entre os dois saberes. Portanto, não se trata de um raciocínio meramente experimental ou formal. Seus estudos tratam do léxico sociológico que se constitui mediante o conflito entre a linguagem teórica, conceitual e formal e as exigências da observação diante da realidade histórica. Estamos no campo das Ciências Sociais ou Históricas, que, para o autor, são "ciências sintéticas", cujo objetivo é reconstruir a realidade pela interpretação. Assim, é capaz de construir teorias sobre as experiências sociais, ao mesmo tempo em que a experiência também age sobre as teorias. Entretanto, produzem saberes provisórios diante da realidade infinita.

Tais asserções comprometem uma forma de raciocínio sequencial, mas que constrói suas bases em métodos diversos que recorrem a pesquisas diferenciadas, com a elaboração de conceitos gerais e mais precisos, particulares. Diz Passeron: "A sociologia é ao mesmo tempo este conjunto sequencial de conhecimentos e este conjunto retalhado de raciocínios" (1995, p. 40). Relevante é não desindexar conceitos e saberes das relações constitutivas da realidade. 
Então, não existe um método científico. Seria, reconhecidamente, impossível para qualquer texto listar a totalidade dos métodos utilizados nas ciências, até porque o aprendizado dos métodos que interessarão ao pesquisador acompanhará sua especialização em determinado campo de conhecimento. O objeto de estudo de cada ciência terminará por desenhar quais métodos específicos devem ser utilizados.

O campo dos problemas que constituem objeto de curiosidade das Ciências Sociais, por exemplo, é por demais vastos para ser absorvido ou reduzido a uma única disciplina. Trata-se, de acordo com Bruyne, Herman, Schoutheete (1977), de um campo pluridisciplinar, onde cada disciplina, seja a Sociologia, a História, a Economia, a Antropologia, a Psicologia etc., pinça um aspecto particular desse espaço para estabelecer com ele uma relação de conhecimento.

Assim sendo, pode-se considerar que as Ciências Sociais, antes e agora, continuam na condição de constituir-se possibilidade de conhecimento científico como enfatiza Minayo (1994). Pensando dessa maneira, a autora, sob a forma de questionamentos, põe em destaque alguns dos dilemas inerentes à cientificidade das Ciências Sociais, entre os quais: como os pesquisadores podem garantir a objetividade dos resultados de seus estudos sendo eles próprios agentes da realidade pesquisada? A busca da objetividade, própria das ciências da natureza, não descaracterizaria o essencial dos fenômenos e processos sociais cujos sentidos são dados pela subjetividade? Que método geral poderia ser proposto para explorar uma realidade tão marcada pela especificidade e pela diferenciação? Enfim, como garantir a possibilidade de um consenso fundado num compartilhamento de princípios e não de procedimentos?

Difícil não observar que existe hoje, categoricamente, uma ideia de devir na noção de cientificidade. Sendo assim, seria muito complicado enfrentar a experiência das Ciências Sociais com a norma de uma cientificidade anteriormente constituída. Contudo, Minayo (1994) lembrra que "[a] pesquisa social é sempre tateante, mas, ao progredir, elabora critérios de orientação cada vez mais preciosos” (p. 13).

Importa, ainda, comentar sobre a historicidade do objeto das Ciências Sociais. As sociedades humanas vivem em espaços determinados que expressam formação social e configuração específicas. E, no dizer de Cury (1985, p. 30), “cada realidade no seu devir é limitado por outra, e assim a totalidade é sempre aberta a novas determinações. Nesse movimento, cada elemento contém os anteriores e se abre a novas determinações". 
Dessa forma, a marca da provisoriedade, do dinamismo e da especificidade estão presentes em qualquer questão social com fortes reflexos sobre a sua possibilidade de explicação.

Outra noção significativa no interior da teoria do conhecimento é a da relação do sujeito (aquele que observa e conhece o fenômeno) - por muitos considerados polo ativo do conhecimento - , com o objeto (aquilo que é observado e conhecido) - por alguns entendido como o polo passivo do ato de conhecer. Hoje já existe uma profunda compreensão da existência de uma nítida identidade entre sujeito e objeto em todo e qualquer ato de investigação. Sujeito e objeto se determinam mútua e incessantemente. Essa compreensão é muito importante para a concretização do desejo da objetivação, e não da objetividade, esta, utopia da Ciência. A visão de mundo do pesquisador e de seu campo de estudo está presente em todo o processo do conhecimento desde a escolha e concepção do objeto, passando pelos resultados do trabalho e sua aplicação.

$\mathrm{Na}$ verdade, o sujeito do conhecimento não constrói seu objeto isolando-se ou fazendo interrogações a si mesmo. Ele, como já referido anteriormente, o (re) constrói, em nível do pensamento, formulando indagações sobre a realidade a qual ele próprio pertence em determinado tempo e espaço definidos. Além do mais, não é apenas o pesquisador que empresta sentido à sua produção intelectual, mas todas as pessoas envolvidas, os grupos e as sociedades.

Outra evidência é que todo conhecimento se vincula a necessidades reais. Todo problema científico será sempre, antes, um problema da vida prática, vincula-se a necessidades reais, faz parte da vida. Toda investigação, portanto, inicia-se com um problema que, por sua vez, articula-se a conhecimentos anteriores. Assim, cai por terra qualquer pretensão de um conhecimento puro. Sobre esse aspecto, Mirian Limoeiro se pronuncia:

[...] o conhecimento puro - fruto de uma pura extração de verdades prontas e já contidas como tal na realidade, ou de uma pura construção lógica inteiramente contida no plano teórico — é uma ilusão, ilusão que só é possível pela abstração de momentos da produção de um conhecimento, desconhecendo a sua trajetória e os estímulos, impulsos e resistências ligados a ela. (Cardoso, 1982, p. 10)

O vínculo com a prática perpassa necessariamente todo o curso do conhecimento, seja como produto, seja como processo. A saber, tanto na condição de teoria quanto na condição de método. Admitida a historicidade e a teoricidade do sujeito 
e do objeto, numa empreitada investigativa, não há como almejar que o conhecimento consiga produzir teoricamente uma completa e definitiva representação do objeto investigado.

\section{Algumas consideraç̃ões}

Por fim, importa enfatizar que o conhecimento científico se concretiza com o recurso e exigências da metodologia científica. A metodologia é parte da lógica dos procedimentos científicos. Ela ajuda a compreender e interpretar os produtos e também o próprio processo de investigação. Em sua composição, as diversas abordagens científicas revelam igualmente a diversidade de métodos que desempenham papel preponderante.

Relevante é compreender que os conhecimentos, por mais rigorosos que sejam seus mecanismos de controle, exatidão e transparência, mesmo assim são incompletos e parciais, põem em dúvida a objetividade, essa utopia da ciência moderna.

Toda resposta científica dependerá da fase de desenvolvimento do seu objeto assim como do desenvolvimento teórico alcançado até então. O pesquisador, por sua vez, partirá da problemática do seu tempo, da realidade em que se encontra inserido. Assim, a seleção do objeto, os objetivos da investigação, os recursos disponíveis, a maior ou menor ênfase na atividade científica definem prioridades postas pelas próprias relações sociais em cada momento histórico. Todo conhecimento é, portanto, ideológico, comprometido, veicula intenções e visões de mundo historicamente constituídas mesmo que seus resultados e contribuições ultrapassem os interesses de seu desenvolvimento.

Por outro lado, o conhecimento científico estará sempre aberto a novas contribuições. O resultado de uma pesquisa, operacionalizada com o rigor do método, consegue dar conta da realidade, porém não de toda realidade. O mais importante será dar conta do que seja mais essencial nessa realidade. Essa busca é o que se convencionou chamar objetivação, ou seja, o rigor no manuseio do instrumental teórico e técnico para se penetrar nas experiências profundas do real.

As Ciências Sociais possuem instrumentos e teorias capazes de fazer uma aproximação da suntuosidade que é a vida dos seres humanos em sociedades, ainda que de forma incompleta, imperfeita e insatisfatória. Para isso, ela aborda o conjunto de 
expressões humanas constantes nas estruturas, nos processos, nos sujeitos, nos significados e nas representações. (Minayo, 1994, p. 15)

É importante dizer que se trata de um rigor flexível para alcançar a objetivação. Este artigo chama a atenção para a crítica que pesquisadores têm feito sobre a perspectiva da anterioridade do método, da mesma forma que já foi comentado sobre a tradição da razão cartesiana, que tenta produzir conhecimento em linha reta, segura, sem se importar com o desalinhamento incerto e provisório das teorias e das realidades materiais e simbólicas. Para alguns desses pesquisadores, o método que se coloca anterior à pesquisa, à inserção no campo "é uma fábula", uma "ilusão", como se fosse anterior aos conteúdos do mundo vivido, desconsiderando a história viva do pensamento e com ela as dificuldades, os erros e as confusões da experiência. (Najmanovich, 2003).

A perspectiva passa pela compreensão da realidade em sua diversidade, preocupa-se menos com essência e a totalidade e mais com contextos relacionais variantes diante dos movimentos concretos e invisíveis que fazem parte das experiências e também da dinâmica de construção do pesquisador. Os métodos ajudam a referenciar a perspectiva dialógica entre conceitos e empiria, auxiliando a interação com a realidade, constituindo novas relações e experimentando novas articulações. Os métodos servem para observar fenômenos e indivíduos que nem sempre são os mais significativos e notados, mas que escondem, por trás da sua invisibilidade, possibilidades de alcançar mais conhecimento. Como diz Esteban (2003, p. 128), é preciso "ressaltar a parte, o episódico, o ordinário" a partir dos instrumentos da pesquisa que contribuam para maior compreensão das relações instituídas e instituintes do universo pesquisado.

Contudo, esta concepção não significa abandonar o rigor metodológico, a condução necessária do pesquisador, imprescindíveis à pesquisa. Mas isto não fecha o caminho. Ao contrário, é flexível diante dos dilemas do imponderável, do incerto. A meta é articular teorias e caminhos metodológicos, conquistados e acumulados pela ciência e sua racionalidade, com caminhos arriscados constitutivos de novas e incessantes racionalidades cotidianas, em que o pesquisador precisa se aventurar diante das contradições que compõem sempre as experiências de homens e mulheres.

Como se nota, os desafios são imensos quando alguém se propõe a buscar explicações para a dinâmica social. Esses desafios, porém, não são intransponíveis. É preciso preparo para acolher a surpresa. Isto significa que a teoria deverá assumir sua tensão entre o que está posto em forma de abstração ampla da realidade social 
e o que está reposto com base naquilo que a dinâmica do real põe para ser pensado. Afinal de contas, concordando com Shakespeare, "há mais coisas entre o céu e a terra que supõe nossa vã filosofia”.

\section{Recebido em 18/6/2012 a Aprovado em 10/12/2012}

\section{Referências bibliográficas}

ARENDT, Hannah. A vida do espirito. Rio de Janeiro: Relume-Dumará, 1992.

BOURDIEU, Pierre. Coisas ditas. Trad. de Cássia R. da Silveira e Denise Moreno Pegorim. São Paulo: Brasiliense, 2004.

BRUYNE, Paul de; HERMAN, Jacques; SCHOUTHEETE, Marc de. Dinâmica da pesquisa em ciências sociais. 2. ed. Trad. de Ruth Joffily, prefácio de Jean Ladrière. Rio de Janeiro: Francisco Alves, 1977.

CARDOSO, Míriam Limoeiro. Prefácio. In: SILVA, Maria de Guadalupe. Ideologia e Serviço Social: reconceituação latino-americana. São Paulo: Cortez, 1982. p. 10.

COHN, Gabriel. Max Weber. Sociologia. São Paulo: Ática, 2000. (Col. Grandes Cientistas Sociais.)

CURY, Carlos R. Jamil. Educação e contradição: elementos metodológicos para uma teoria crítica do fenômeno educativo. São Paulo: Cortez, 1985.

DA MATTA, Roberto. O ofício de etnólogo, ou como ter "antropological blues". In:

A aventura sociológica: objetividade, paixão, improviso e métodos na pesquisa social. Rio de Janeiro: Zahar Editores, 1978.

Relativizando: uma introdução à antropologia social. Rio de Janeiro: Rocco, 1987.

ESTEBAN, Maria Teresa. Sujeitos singulares e tramas complexas: desafios cotidianos ao estudo e à pesquisa. In: GARCIA, Regina Leite (Org.). Método, métodos e contramétodo. São Paulo: Cortez, 2003.

GINZBURG, Carlo. Sinais: raízes de um paradigma indiciário. In: . Mitos, emblemas, sinais: morfologia e história. São Paulo: Companhia das Letras, 1989.

HABERMAS, Jürgen. Teoria de la acción comunicativa: complementos y estúdios previos. Madrid: Catedra, 1994.

HESSEN, Johannes. Teoria do conhecimento. 7. ed. Trad. de António Correia. Coimbra: Armênio Amado, editor, Sucessor, 1980. 
HORKHEIMER, Max. Teoria crítica I. São Paulo: Perspectiva, 1990.

KUHN, Thomas S. A estrutura das revoluções cientificas. 9. ed. Trad. de Beatriz Vianna Bocira e Nelson Bocira. São Paulo: Perspectiva, 2006. (Debates, v. 115.)

LADRIÈRE, Jean. Prefácio. In: BRUYNE, Paul de; HERMAN, Jacques; SCHOUTHEETE, Marc de. Dinâmica da pesquisa em ciências sociais. 2. ed. Trad. de Ruth Joffily. Rio de Janeiro: Francisco Alves, 1977.

LÖWY, Michael. Ideologia e ciência social: elementos para uma análise marxista. São Paulo: Cortez, 1985.

MARTINS, José de Souza; ECKERT Carmélia; NOVAES Sylvia Caiuby. O imaginário e o poético nas ciências sociais. Bauru: Edusc, 2005.

MARTINS, José de Souza. A sociabilidade do homem simples. São Paulo: Hucitec, 2000.

MILLS, C. WRIGHT. A imaginação sociológica. 5. ed. Trad. de Walternsir Dutra. Rio de Janeiro: Zahar Editores, 1980.

MINAYO, Cecília de Souza (Org.). Pesquisa social: teoria, método e criatividade. Petrópolis: Vozes, 1994. 1993.

O desafio do conhecimento: pesquisa qualitativa em saúde. 2. ed. São Paulo: Hucitec,

MORIN, Edgar. Introdução ao pensamento complexo. 2. ed. Lisboa: Instituto Piaget, 1991. . Os sete saberes ligados à educação do futuro. São Paulo: Cortez; Brasília: Unesco, 2000.

NAJMANOVICH, Denise. O feitiço do método. In: GARCIA, Regina Leite. Método métodos e contramétodo (Org.). São Paulo: Cortez, 2003.

NETTO, José Paulo. A controvérsia paradigmática nas Ciências Sociais. Cadernos ABESS, São Paulo, n. 5, 1992.

ORTIZ, Renato. As ciências sociais e a diversidade de sotaques. Revista Brasileira de Ciências Sociais, Associação Nacional de Pós-Graduação e Pesquisa em Ciências Sociais. São Paulo, v. 27, n. 78, p. 7-24, fev. 2012.

PASSERON, Jean-Claude. O raciocínio sociológico: o espaço não popperiano do raciocínio natural. Petrópolis: Vozes, 1995.

SILVA, Maria de Guadalupe. Ideologias e Serviço Social: reconceituação latino-americana. São Paulo: Cortez, 1982.

WEBER, M. Economia e sociedade. Brasília: Ed. UnB, 1991. 